\title{
METODOLOGIA PARA PRODUÇÃO DE Metarhizium anisopliae (METSCH.) SOROKIN EM CULTIVO SUBMERSO: ESPORULAÇÃO DA BIOMASSA, EFEITO DA CONCENTRAÇÃO DE AÇÚCAR E CUSTO DO INOCULANTE ${ }^{1}$
}

\author{
METHODOLOGY FOR PRODUCTION OF Metarhizium anisopliae (METSCH.) \\ SOROKIN IN SUBMERGED CULTIVATION: BIOMASS SPORULATION, \\ SUGAR CONCENTRATION EFFECT AND INOCULANT COST
}

\author{
Sonia Regina de Mello Pereira ${ }^{2}$ Augusto Ferreira da Eira ${ }^{3}$
}

RESUMO

Desenvolveram-se um método de cultivo e um meio de cultura para produção massal do fungo Metarhizium anisopliae (Metsch.) Sorokin, 1883, com maior pureza e concentração de conídios. Este método envolveu o cultivo submerso da linhagem M-61 do entomopatógeno em meio líquido de arroz parboilizado, extrato de levedura, extrato do percevejo da soja (Nezara viridula (L., 1758) Hemiptera, Pentatomidae), sob seis diferentes níveis de concentração de açúcar $\left(0,2,4,6,8,10 \mathrm{~g} \mathrm{l}^{-1}\right)$, além do meio convencional sólido de arroz em grão. As biomassas obtidas foram separadas através de tela de nylon (63 mesh) e dispostas em estufa para a esporulação. Os efeitos dos tratamentos foram avaliados pelos parâmetros pesos fresco e seco do micélio, número de conídios por grama de substrato, viabilidade e patogenicidade dos conídios sobre o percevejo. Observou-se que $2.0 \mathrm{~g}$ $l^{-1}$ de açúcar em meio de cultura de extrato de $N$. viridula produziu o dobro do número de conídios por grama de substrato em relação à concentração de $10.0 \mathrm{gl}^{-1}$, a um custo 51 vezes inferior ao obtido no processo convencional de produção do fungo. A viabilidade não foi afetada nos diferentes meios utilizados. Não ocorreram diferenças significativas na patogenicidade em função dos meios de cultura e métodos de cultivo.

Palavras-chave: Metarhizium anisopliae, cultivo submerso, custo de produção, Nezara viridula.

\section{SUMMARY}

A method of cultivation and a culture medium were developed aiming at the mass production of fungus Metarhizium anisopliae (Metsch.) Sorokin, 1883, with great concentration and purity of conidia. This method involved the M-61 strain of entomopathogenic fungus in liquid medium of rice, yeast extract, soybean bug extract (Nezara viridula (L., 1758) Hemiptera, Pentatomidae), under six differents concentrations of sugar $(0,2$, $\left.4,6,8,10 \mathrm{~g} \mathrm{l}^{-1}\right)$, and the solid conventional medium of rice grains. The biomasses obtained were filtered and put in an incubator to promote sporulation. The treatments were evaluated through the parameters wet and dry-weight of micelium, number of conidia per gram of substrate, viability and pathogenicity of conidia against the bug. It was observed that the sugar concentration of $2.0 \mathrm{gl}^{-1}$ in extract of $\mathrm{N}$. viridula produced two times more conidia per gram of substrate when compared to $10.0 \mathrm{~g} \mathrm{l}^{-1}$, and 51 times cheaper than the conventional process of production of fungus. Viability was not affected by the different culture media. Significant differences did not occur in the pathogenicity among culture media and cultivations methods.

Key words: Metarhizium anisopliae, submerged cultivation, production cost, Nezara viridula.

\section{INTRODUÇÃO}

A produção, em larga escala no Brasil, do fungo M. anisopliae teve início na região dos canaviais nordestinos, objetivando o controle biológico da cigarrinha da cana-de-açúcar, Mahanarva posticata (Stal, 1855).

\footnotetext{
${ }^{1}$ Parte da Dissertação de Mestrado em Proteção de Plantas do primeiro autor, Faculdade de Ciências Agronômicas da Universidade Estadual Paulista, Botucatu, SP. Bolsa de estudos concedida pela CAPES.

${ }^{2}$ Engenheiro Agrônomo, Mestre em Proteção de Plantas, Doutorando em Fitotecnia, Departamento de Horticultura e Silvicultura, Faculdade de Agronomia, Universidade Federal do Rio Grande do Sul, CP 776, 91501-970, Porto Alegre, RS. E-mail: sonmello@pro.via- rs.com.br. Autor para correspondência.

${ }^{3}$ Engenheiro Agrônomo, Professor Titular, Departamento de Defesa Fitossanitária, Faculdade de Ciências Agronômicas, Universidade Estadual Paulista.
} 
A produção do fungo em meio sólido de arroz em grão foi comprovada por GUAGLIUMI $\boldsymbol{e} t$ al. (1974), COSTA et al. (1974) e VILLACORTA (1976); assim como em meio sólido de farinha de arroz (COSTA \& MAGALHÃES, 1974; FRIGO \& AZEVEDO, 1986).

A partir da década de 60 , algumas pesquisas direcionaram-se para a produção de fungos entomopatogênicos em cultivo submerso, visando à produção de maior número de conídios infectivos a um menor custo, visto ser esta a condição essencial para o uso de microrganismos no controle biológico de insetos (ADAMEK, 1965). Este método utiliza meio líquido inoculado disposto em agitador a 150 rpm. A biomassa é filtrada, lavada com água destilada, pesada e desidratada. A reidratação de amostra da biomassa fornece material para os testes de viabilidade (ADAMEK, 1965; ROBERTS, 1966; BARNES et al., 1975). Na literatura nacional, os trabalhos sobre produção do fungo em cultivo submerso diferem quanto a esta metodologia, pois não se promove a agitação (BASTOS CRUZ et al., 1983; GREGHI, 1987); os frascos são expostos à luz por 10 horas por dia (BASTOS CRUZ et al., 1985) e vários meios líquidos à base de melaço, farinha de soja e sais minerais são utilizados (ALVES, 1986).

Desta forma, observa-se que os autores ignoraram que sob cultivo submerso não ocorre esporulação e, para a obtenção de conídios, era necessário deixar os sistemas em repouso (ALVES, 1986), ou trabalharam apenas com a biomassa desidratada e, portanto, sem conídios.

No presente trabalho, estudou-se os efeitos de meios de cultura e de diferentes concentrações de açúcar na produção massal de M. anisopliae.

\section{MATERIAL E MÉTODOS}

O trabalho foi realizado no Departamento de Defesa Fitossanitária da Faculdade de Ciências Agronômicas da UNESP, Campus de Botucatu (SP). Utilizou-se a linhagem M-61 do fungo $\boldsymbol{M}$. anisopliae, cedida pelo Centro Nacional de Pesquisa de Soja - CNPSo de Londrina (PR). A criação do percevejo Nezara viridula (L., 1758) foi mantida de acordo com a metodologia descrita por CORREAFERREIRA (1985).

Os meios de cultura utilizados foram: meio sólido de arroz em grão (50\% de umidade); meio líquido de extrato de arroz parboilizado em pó (1,5\%); meio líquido de extrato do percevejo $N$. viridula $(0,2 \%)$ e glicose $(1,0 \%)$, além das diferentes concentrações de sacarose comercial $(0,2,4,6,8$ e

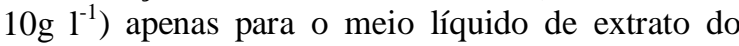

percevejo e meio líquido de extrato de levedura $(0,2 \%)$. Para a preparação do meio natural de extrato de $\boldsymbol{N}$. viridula, os percevejos, secos em estufa a 105 $\pm 5^{\circ} \mathrm{C}$ por 24 horas, foram fragmentados em gral de porcelana, fervidos por 10 minutos em água destilada e o extrato foi filtrado em gase esterilizada e acrescido dos ingredientes restantes. Todos os meios de cultura foram autoclavados a $120^{\circ} \mathrm{C}$ por $30 \mathrm{mi}-$ nutos.

Nos diferentes tratamentos, os frascos receberam $1,0 \mathrm{ml}$ da suspensão de conídios de Metarhizium $\left(10^{6} \mathrm{con} \mathrm{ml}^{-1}\right)$ obtidos nos respectivos meios sólidos, e foram incubados em agitador rotatório $(114 \mathrm{rpm})$ por 72 horas à temperatura de 27 $+1^{\circ} \mathrm{C}$. O conteúdo dos frascos foi filtrado por sistema de kitassatos associados a uma bomba aspirante (vácuo). Um funil de porcelana com tela de nylon (63 mesh) separou os "pellets" produzidos. Assim, cada biomassa recebeu os respectivos tratamentos de lavagem: sem lavagem, uma lavagem (500ml) com água destilada e duas lavagens $(500 \mathrm{ml}$ cada) com água destilada.

A esporulação deu-se em câmara de crescimento a $26+1^{\circ} \mathrm{C}$, umidade relativa de 65 a $85 \%$ e fotoperíodo de 16 horas, durante 72 horas. A biomassa foi desidratada em estufa a $32^{\circ} \mathrm{C}$ e fluxo de aeração de $0,01 \mathrm{ll}^{-1} \mathrm{~min}^{-1}$, durante 48 horas. A partir destas, obtiveram-se as suspensões de conídios.

Prepararam-se quatro repetições para o meio sólido de arroz em grãos, seis para os meios com diferentes concentrações de açúcar e dezoito para os demais meios. A viabilidade dos conídios foi verificada em três repetições por tratamento, pela contagem de conídios germinados e não germinados em 10 campos aleatórios por placa.

Para a avaliação da patogenicidade do fungo sobre o percevejo, utilizaram-se gaiolas de PVC branco com $75 \mathrm{~mm}$ de diâmetro e $5 \mathrm{~cm}$ de altura com tela de malha fina numa das extremidades e dispostas em placa de Petri contendo papel filtro. Três potenciais de inóculo $\left(2,3 \times 10^{5}, 2,3 \times 10^{6}\right.$ e $2,3 \times 10^{7}$ conídios $\mathrm{ml}^{-1}$ ) foram aplicados com pulverizador de Vilbs, em quatro repetições de 15 insetos por tratamento, em experimento inteiramente casualizado. Dos insetos mortos, reisolou-se o patógeno, segundo metodologia descrita por ALVES (1986).

Para a estimativa do custo por grama de substrato de cada meio de cultura, têm-se: coleta manual do percevejo (300 insetos homem ${ }^{-1}$ hora $^{-1}$, $1 \mathrm{~g}$ de peso seco $=7$ insetos) corresponde a US\$ $0,00091 \mathrm{~g}^{-1}$; glicose a US\$ $0,00136 \mathrm{~g}^{-1}$; extrato de levedura a US\$ $0,00273 \mathrm{~g}^{-1}$; sacarose comercial a US\$ $0,00055 \mathrm{~g}^{-1}$; e arroz parboilizado a US\$ $0,00064 \mathrm{~g}^{-1}$. 


\section{RESULTADOS E DISCUSSÃO}

\section{O fungo $M$. anisopliae}

produziu maior quantidade de matéria fresca e seca em meio de extrato do percevejo (tabela 1). A metodologia proposta com o emprego desse meio de cultura líquido natural é bastante promissora (BASTOS CRUZ et al., 1983; BATISTA FILHO et al., 1985), já que a melhor avaliação da produção de biomassa fúngica é através do parâmetro peso seco (LATGÉ, 1980; BASTOS CRUZ et al., 1983; CAMPBELL et al., 1983; GREGHI, 1987). Observa-se que, na ausência da lavagem, os pesos frescos e secos representam a quantidade de biomassa produzida pelo fungo e os sólidos solúveis em suspensão, cujos valores se reduzem de acordo com o número de lavagens. COCHRANE (1958) e FRIGO \& AZEVEDO (1986) mencionam que substratos pobres levam à indução de esporulação de fungos com maior produção de conídios.

Verifica-se que a produção de biomassa em meio de $N$. viridula não diferiu quando utilizouse $2,0 \mathrm{~g} \mathrm{l}^{-1}$ ou $10,0 \mathrm{~g} \mathrm{l}^{-1}$ de sacarose comercial (tabela 2) e que a concentração de $2,0 \mathrm{~g}^{-1}$ sobressaiu-se quanto ao número de conídios produzidos (tabela 2), com um custo 51 vezes inferior ao meio convencional (tabelas 3 e 4). Cabe ressaltar que uma das características mais desejáveis de um meio de cultura para produção de conídios infectivos a determinado inseto é a produção do maior número possível de conídios por grama de substrato a um menor custo (ADAMEK, 1965; GOETTEL, 1984).

Com uma lavagem, embora os pesos da matéria seca no meio de extrato de $N$. viridula e de arroz tenham sido iguais, a produção de conídios foi menor no meio de arroz (tabela 1 ), confirmando a hipótese do meio de cultura natural de um inseto poder proporcionar melhor desempenho do microrganismo em termos de produção de conídios (NAHAS \& ARAI, 1987). Também o uso de meios naturais complexos pode evitar a seleção de mutantes nutricionais menos patogênicos muito comum quando se utiliza meios artificiais (MARSHALL, 1915; POCHON \& BARJAC, 1958; STANIER $\boldsymbol{e t}$ al., 1969).

Tabela 2 - Peso médio (g) de matéria fresca e seca da biomassa fúngica, número médio de conídios por grama de substrato e viabilidade média dos conídios produzidos em meio de $N$. viridula sob diferentes concentrações de sacarose comercial.

\begin{tabular}{|c|c|c|c|c|c|c|}
\hline \multirow[t]{2}{*}{ Parâmetros } & \multicolumn{6}{|c|}{ Concentração de Sacarose Comercial } \\
\hline & 0 & 2 & 4 & 6 & 8 & 10 \\
\hline $\begin{array}{l}\text { Peso médio da matéria } \\
\text { fresca }(\mathrm{g})\end{array}$ & $7,5000 \mathrm{c}$ & $14.0333 \mathrm{~b}$ & $17.7000 \mathrm{a}$ & $162500 \mathrm{ab}$ & $187667 \mathrm{a}$ & $16500 \mathrm{ab}$ \\
\hline $\begin{array}{l}\text { Peso médio da matéria } \\
\text { seca }(\mathrm{g})\end{array}$ & $0,2000 \mathrm{a}$ & $0,4000 \mathrm{a}$ & $1,8667 \mathrm{a}$ & $0,6167 \mathrm{a}$ & $1,2000 \mathrm{a}$ & $0,9500 \mathrm{a}$ \\
\hline $\begin{array}{l}\text { Número médio de } \\
\text { conídios/g substrato } \\
\text { Viabilidade média }(\%)\end{array}$ & $\begin{array}{c}4,4944 \mathrm{~d} \\
\text { nd }\end{array}$ & $\begin{array}{c}6,000 \mathrm{a} \\
71,5875 \mathrm{a}\end{array}$ & $\begin{array}{l}5,5355 \mathrm{~b} \\
73,7033 \mathrm{a}\end{array}$ & $\begin{array}{l}5,3601 \mathrm{~b} \\
68,0736 \mathrm{a}\end{array}$ & $\begin{array}{l}5,1705 \mathrm{c} \\
73,4040 \mathrm{a}\end{array}$ & $\begin{array}{l}4,8771 \mathrm{c} \\
69,1102 \mathrm{a}\end{array}$ \\
\hline
\end{tabular}

Médias seguidas da mesma letra, na coluna, não diferem significativamente entre si, pelo teste de Tukey $(\mathrm{P}<0,05)$.

nd = não determinado.

Ciência Rural, v. 29, n. 3, 1999. 
Tabela 3 - Composição dos custos em US\$ (dólar comercial americano) dos substratos utilizados para produção de M. anisopliae.

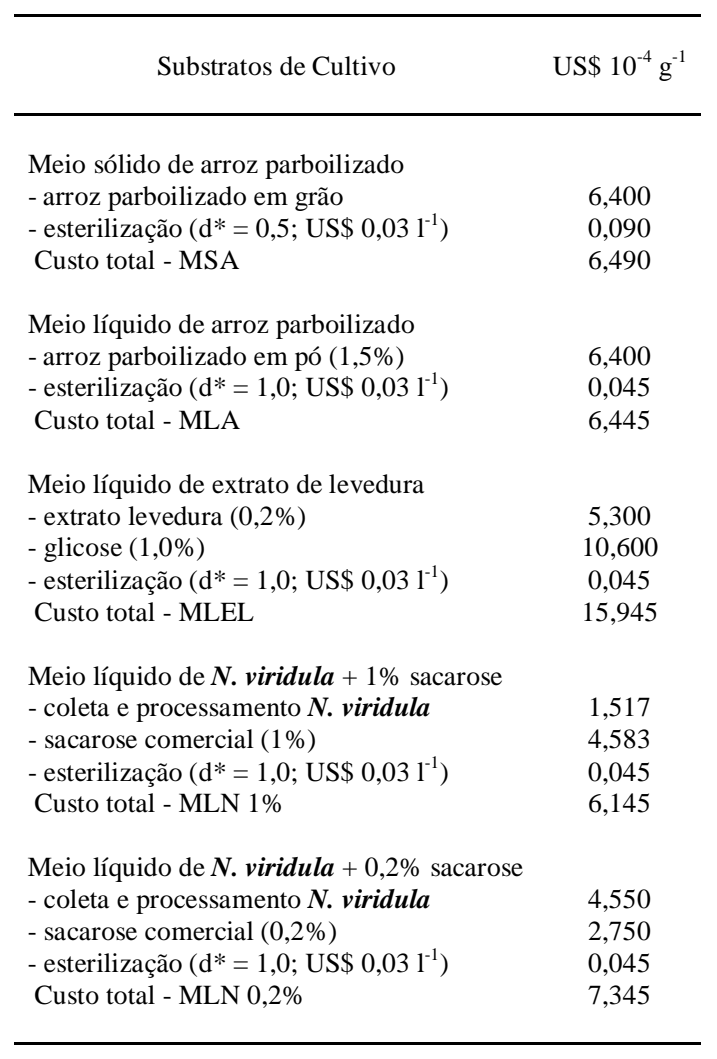

$* \mathrm{~d}=$ densidade do arroz em grão é aproximadamente $0,5 \mathrm{~g} \mathrm{~cm}$ ${ }^{3} \mathrm{e}$ em meio líquido é de aproximadamente $1,0 \mathrm{~g} \mathrm{~cm}^{-3}$. A autoclave de 50 litros consome $1,5 \mathrm{kWh}$ (esterilização a $1 \mathrm{~atm}$ por $30 \min )$ a US $\$ 0,15$ por $\mathrm{kWh}$.
O número médio de conídios produzidos por grama de substrato em meio de arroz em grão foi inferior ao meio de $N$. viridula, utilizando-se a técnica de esporulação proposta neste trabalho, enquanto que a viabilidade e a patogenicidade foram similares (tabela 5, tabela 6). Alguns trabalhos preconizam resultados similares de esporulação, entretanto a técnica utilizada foi em bandejas, mantendose o sistema em repouso de tal forma que a biomassa esporulasse apenas na superfície (BASTOS CRUZ et al., 1985; ALVES, 1986). Entretanto, os fungos não esporulam em cultivo submerso (LILLY \& BARNET, 1951; COCHRANE, 1958; METZ \& KOSSEN, 1977; EIRA, 1981), mas somente com a disposição da biomassa sob aeração direta é que ocorre a estimulação da esporulação, tal como observado neste trabalho. Na literatura consultada, os estudos relativos ao processo de produção do fungo M. anisopliae em meio líquido não ousaram processar a biomassa em condições favoráveis à esporulação, nem tampouco a produziram em verdadeiro cultivo submerso. Estas técnicas são realmente vantajosas em termos biotecnológicos e são muito comuns, inclusive, em trabalhos sobre tratamento de efluentes da indústria de chapas de madeira (EIRA, 1981), na microbiologia industrial (PRESCOTT \& DUNN, 1959; RHODES \& FLETCHER, 1969; JORGENSEN, 1978) e em outros processos industriais (METZ \& KOSSEN, 1977).

Verifica-se que a viabilidade dos conídios nestes ensaios não foi influenciada pelos tratamentos realizados (tabela 1 e 2, tabela 5). Nos testes de patogenicidade, a interação entre os meios de cultura e os potenciais de inóculo não evidenciaram diferenças em relação aos tratamentos empregados (tabela 6). Verificou-se que o contato direto dos insetos com os conídios não foi suficiente para provocar infecção, apesar da concentração empregada ter sido eficaz contra Ceratitis capitata (GARCIA et al., 1984) e Diatraea saccharalis (ALMEIDA \& ALVES, 1982). É possível que as diferentes respostas do inseto ao patógeno estejam relacionadas à necessidade de nutrientes específicos para o início da germinação dos conídios (SAMUELS $\boldsymbol{e t}$ al., 1989), à adaptação e

Ciência Rural, v. 29, n. 3, 1999. 
Tabela 5 - Log natural e viabilidade do número médio de conídios de M. anisopliae por grama de substrato produzidos em meio convencional de arroz em grão. Dados originais do número de conídios transformados em logarítimo natural.

\begin{tabular}{ccc}
\hline Repetições & $\begin{array}{c}\text { Log natural do número } \\
\text { de conídios } \mathrm{g}^{-1}\end{array}$ & $\begin{array}{c}\text { Viabilidade média } \\
(\%)\end{array}$ \\
\hline 1 & 17,9827 & 94,32 \\
2 & 17,9909 & 93,90 \\
3 & 17,8597 & 92,98 \\
4 & 18,3799 & nd \\
Média & 18,0533 & 93,70 \\
\hline
\end{tabular}

nd = não determinado.

conseqüente especificidade de uma linhagem do fungo a determinada espécie de inseto hospedeiro (FERRON et al., 1972; FERRON \& ROBERT, 1975; TULLOCH, 1976; BARBOSA et al., 1985) e aos métodos e condições de inoculação e às fases de desenvolvimento do inseto (FOLEGATTI $\boldsymbol{e t} \boldsymbol{a l}$., 1990).

Tabela 6 - Número médio de percevejos de $\boldsymbol{N}$. viridula mortos devido à infecção pelo fungo $M$. anisopliae produzido nos diferentes meios de cultura sob os potenciais de inóculo.

\begin{tabular}{lccc}
\hline & \multicolumn{3}{c}{ Potenciais de inóculo } \\
\cline { 2 - 4 } $\begin{array}{c}\text { Meios de } \\
\text { cultura }\end{array}$ & 10.000 & 100.000 & 1.000 .000 \\
\cline { 2 - 4 } $\mathrm{N}+\mathrm{I}$ & 0,25 & 0,25 & 1,75 \\
Extrato de levedura & 0,5 & 1,0 & 1,25 \\
Arroz & 0 & 0,25 & 0 \\
\hline
\end{tabular}

\section{REFERÊNCIAS BIBLIOGRÁFICAS}

ADAMEK, L. Submerse cultivation of the fungus Metarhizium anisopliae (Metsch.). Folia Microbiologic, Prague, n. 10, p. 255-267, 1965.

ALMEIDA, L.C., ALVES, S.B. Testes preliminares de dosagens do Metarhizium anisopliae (Metsch.) Sorok., para o controle da broca da cana, Diatraea saccharalis (Fabr.). Brasil Açucareiro, Rio de Janeiro, v. 99, p. 35-38, 1982.
ALVES, S.B. 1986. Controle microbiano de insetos. São Paulo: Manole, 1986. 407p.

BARBOSA, F.R., MOREIRA, W.A, SANTOS, G. Efeito de sucessivas repicagens em arroz na virulência de Metarhizium anisopliae (Metsch.) Sorokin para Deois flavopicta. Pesquisa Agropecuária Brasileira, Brasília, v. 20, n. 10, p. 1115-1118, 1985.

BARNES, G.L., BOETHEL, O J., EIKENBARY, R.D., $\boldsymbol{e} \boldsymbol{t}$ al. Growth and sporulation of Metarhizium anisopliae and Beauveria bassiana on media containing various peptone sources. Journal of Invertebrate Pathology, New York, v. 25, n. 3, p. 301-305, 1975.

BASTOS CRUZ, B.P., ABREU, O C., OLIVEIRA, D.A, $\boldsymbol{e}$ t al. Crescimento de Metarhizium anisopliae (Metsch.) Sorokin em meios de cultura naturais, líquidos. O Biológico, São Paulo, v. 49, n. 5, p. 111-116, 1983.

BASTOS CRUZ, B.P., OLIVEIRA, D.A, CARDELLI, M.A, et al. Produção massal de esporos de Metarhizium anisopliae (Metsch.) Sorokin em meios de cultura naturais de arroz e de macerado de feijão. O Biológico, São Paulo, v. 51, n. 7, p. 169-174, 1985.

BATISTA FILHO, A., BASTOS CRUZ, B.P., CAMARGO, L.M.P.C.A, et al. Crescimento de Beauveria sp., isolado de bicudo do algodoeiro (Anthonomus grandis Boheman), em meios de cultura naturais, líquidos. O Biológico, São Paulo, v. 51, n. 1, p. 17-21, 1985.

CAMPBELL, R.K., BARNES, G.L., CARTWRIGHT, B.O, et al. Growth and sporulation of Beauveria bassiana and Metarhizium anisopliae in a basal medium containing various carbohydrate sources. Journal of Invertebrate Pathology, New York, v. 41, n. 1, p. 117-121, 1983.

COCHRANE, V.W. Physiology of fungi. New York: John Wiley \& Sons, 1958. 524 p.

CORRÊA-FERREIRA, B.S. Criação massal do percevejo verde Nezara viridula (L.). Londrina: EMBRAPA - Centro Nacional de Pesquisa de Soja, 1985. 16 p. Documentos 11.

COSTA, M.D.M., MAGALHÃES, C.D. Um novo meio de cultura para o fungo entomógeno Metarhizium anisopliae (Metsch) Sorokin, parasito da "cigarinha" das pastagens. Boletim do Instituto Biológico da Bahia, Salvador, v. 13, n. 1, p. 57-60, 1974.

COSTA, M.D.M., MATTA, E.A.F., MAGALHÃES, C.D., $\boldsymbol{e} \boldsymbol{t} \boldsymbol{a l}$. Nova técnica para produção em larga escala do fungo Metarhizium anisopliae (Metschn.) Sorok. em laboratório. Boletim do Instituto Biológico da Bahia, Salvador, v. 13, n. 1, p. 85-89, 1974.

EIRA, A.F. Utilização de fungos micelianos no tratamento de efluentes da indústria de chapas de fibra de madeira de eucalipto. Botucatu-SP, 1981. 182 p. Tese (Livre-Docência) Faculdade de Ciências Agronômicas, Universidade Estadual Paulista, 1981.

FERRON, P., ROBERT, P.H. Virulence of entomopathogenic fungi (fungi imperfecti) for the adults of Acanthoscelides obtectus. Journal of Invertebrate Pathology, New York, n. 25, p. 379-388, 1975. 
FERRON, P., HURPIN, B., ROBERT, P.H. Sur la spécificeté de Metarhizium anisolpliae (Metsch.) Sorokin. Entomophaga Paris, v. 17, n. 2, p. 165-178, 1972.

FOLEGATTI, M.E.G., ALVES, S.B., BOTELHO, P.S.M Pathogenicity of the fungus Metarhizium anisopliae (M.) Sorok for pupae and adults of Apanteles flavipes (Can.). Pesquisa Agropecuária Brasileira, Brasília, v. 25, n. 2, p. 247-251, 1990

FRIGO, S.M., AZEVEDO, J.L. Meios de cultura e produção de conídios em Metarhizium anisopliae (Metsch) Sorokin. Anais da Escola Superior de Agricicultura "Luiz de Queiróz", Piracicaba, v. 43, n. 1, p. 285-293, 1986.

GARCIA, A.S., MESSIAS, C.L, SOUZA, H.M.L. PIEDRABUENA, A E. Patogenicidade de Metarhizium anisopliae var. anisopliae a Ceratitis capitata (Wied) (Diptera, Tephritidae). Revista Brasileira de Entomomologia, São Paulo, v. 28, n. 4, p. 421-424, 1984.

GOETTEL, M.S. A simple method for mass culturing entomopathogenic hyphomycete fungi. Journal of Microbiological Methods, Amsterdam, v. 3, n. 1, p. 15-20, 1984.

GREGHI, J.E. Efeito de diferentes meios de cultura sobre o desenvolvimento do fungo Metarhizium anisopliae (Metsch.) Sorokin, 1883 e sua virulência sobre lagartas da broca da cana (Diatraea saccharalis Fabricius, 1794). Jaboticabal - SP, 1987. 101 p. Monografia (Graduação em Agronomia) - Faculdade de Ciências Agronômicas e Veterinárias, Universidade Estadual Paulista, 1987.

GUAGLIUMI, P., MARQUES, E.J., VILAS BOAS, A M. Contribuição ao estudo da cultura e aplicação de Metarhizium anisopliae (Metsch.) Sorokin no controle da cigarrinha da folha Mahanarva posticata (Stal.) no nordeste do Brasil. Recife: CODECAP, 1974. 56 p. Boletim Técnico n. 3

JORGENSEN, A. Microbiologia de las fermentaciones industriales. Zaragoza: Acribia, 1978. 397 p.

LATGÉ, J.P. Sporulation de Entomophthora obscura Hall et Dunn in culture liquide. Canadian Journal of Microbiology, Otawa, v. 26, p. 1038-1048, 1980.
LILLY, V.G., BARNET, H.L. Physiology of the fungi. New York: MacGraw-Hill, 1951. 464 p.

MARSHALL, C.E. Microbial associations. Science, New York, v. 41 , p. $306-312,1915$.

METZ, B., KOSSEN, N.W.F. Biotechnology review. Biotechnology \& Bioengineering, New York, v. 19, p. 781799, 1977.

NAHAS, E., ARAI, N.N.S. Crescimento e esporulação de Beauveria bassiana em vários meios e condições de cultivo. Revista de Microbiologia, São Paulo, v. 18, n. 1, p. 77-82, 1987

PRESCOTT, S.C., DUNN, C.G. Industrial microbiology. New York: McGraw-Hill, 1959. 945 p.

POCHON, J., BARJAC, H. Traté de microbiologie des sols: applications agronomiques. Paris: Dunod, 1958. 476 p.

RHODES, A., FLETCHER, D.L. Princípios de microbiologia industrial. Zaragoza: Tipo-Línea, 1969. 358 p.

ROBERTS, D.W. Toxins from the entomogenous fungus Metarhizium anisopliae. I. Production in submerged and surface culutres and in inorganic and organic nitrogen media. Journal of Invertebrate Pathology, New York, n. 8, p. 212221, 1966.

SAMUELS, K.D.Z., HEALE, J.B., LLEWELLYN, M Characteristics relating to the pathogenicity of Metarhizium anisopliae toward Nilaparvata lugens. Journal of Invertebrate Pathology, New York, v. 53, p. 25-31, 1989.

STANIER, R.Y., DUODOROFF, M., ADELBERG, E.A Mundo dos micróbios. São Paulo: Edgard Blücher \& USP, 1969. $741 \mathrm{p}$.

TULLOCH, M. The genus Metarhizium. Transaction of the British Mycological Society, Cambridge, v. 66, n. 3, p. 407 411, 1976.

VILLACORTA, A. Técnica para cultura maciça do fungo entomógeno Metarhizium anisopliae (Metsch), em forma granulada. Anais da Sociedade Entomológica do Brasil, Piracicaba, v. 5, n. 1, p. 102-104, 1976.

Ciência Rural, v. 29, n. 3, 1999. 